\title{
De kunstenaar en de dokter
}

\section{Schilderijen als propedeutisch instrument}

\section{Jan Dequeker}

De kunstliefhebber en de dokter hebben meer gemeen dan op het eerste gezicht lijkt. De ene kijkt naar het kunstwerk. De andere kijkt naar de patiënt. Beiden observeren en geven hun visie: de ene een kunstoordeel en de andere een diagnose.

Mijn belangstelling voor de medische aspecten van oude schilderijen werd meer dan dertig jaar geleden gewekt nadat ik in wetenschappelijke medische publicaties uit 1964 en 1974 had gelezen dat reumatoïde artritis een vaak voorkomende chronische gewrichtsaandoening - en vele andere moderne ziekten ontstaan zouden zijn in de Nieuwe Wereld en na 1492 in de Oude Wereld zouden zijn geïntroduceerd. ${ }^{1-2}$

Deze overtuiging had post gevat vanwege het feit dat er uit de periode vóór 1800 geen rapporten zijn waaruit op ondubbelzinnige wijze blijkt dat in medische publicaties, in de literatuur, in kunstwerken of in het paleopathologisch onderzoek het voorkomen van deze ziekte wordt aangetoond. De bewering suggereert ook indirect dat deze chronische ziekten op een of andere manier besmettelijk kunnen zijn en dat het zou gaan om een recente virale mutatie of om een immunologische verandering in voedsel dat afkomstig is uit de Nieuwe Wereld. Deze bewering zette velen - waaronder mezelf - aan om op zoek te gaan naar sporen van deze ziekten van vóór $1800 .^{3}$

Veel grote kunstenaars lieten zich graag inspireren door scènes van medische aard: de dokter, de patiënt, de medische school, de genezing van een zieke. Gezien de drang van schilders naar het dramatische en het ongewone is dat niet zo verrassend. Hoewel een kunstwerk onmiskenbaar een ziekte als onderwerp kan hebben,

Jan Dequeker $(\square)$

Prof. dr. Jan Dequeker is reumatoloog en emeritus hoogleraar

Universitair Ziekenhuis Gasthuisberg, KU Leuven België. blijft de interpretatie ervan toch moeilijk. Foute diagnoses komen vaak voor, bijvoorbeeld omdat men meent een ziekte te zien waar er geen is, of omdat men op het eerste gezicht een medische afwijking denkt te herkennen waar het de uitdrukking blijkt te zijn van een artistieke conventie (bijvoorbeeld maniërisme).

Een klinische diagnose, die gebaseerd is op een zorgvuldige beschouwing van een aandoening zoals die getoond wordt op een schilderij, kan dus ook nog in onze tijd geldig zijn, ook al zijn er geen technische onderzoeken die dit kunnen bevestigen of beschikt men niet over de medische geschiedenis van de patiënt. In sommige gevallen is die geschiedenis er trouwens wel en is deze terug te vinden in schriftelijke historische bronnen.

In vergelijking met onderzoek van beenderresten is een belangrijk voordeel van visuele kunsten als werktuig voor paleopathologisch onderzoek - zoals de schilderkunst - dat de huid en andere zachte weefsels beoordeeld kunnen worden. Ze kunnen afwijkingen vertonen als zwellingen, verkleuringen, verkrampingen of ontwrichtingen. Een ervaren clinicus zal deze meteen herkennen.

Portretten die op bestelling werden geschilderd tonen niet zelden zichtbare ziektesymptomen. Met zijn getrainde oog voor detail en zijn aangeboren belangstelling voor de medemens, was het niet meer dan normaal dat de kunstenaar - althans in de tijd vóórdat de fotografie bestond - schilderde wat hij zag. Hij had allerminst de bedoeling de realiteit te verdoezelen. Dit stelt de hedendaagse medici vaak in staat nauwkeurige diagnoses te stellen aan de hand van de symptomen die door de oude meesters zijn afgebeeld. De op die manier verkregen medische gegevens vormen een waardevolle aanvulling voor de geschiedenis.

Rekening houdend met bovengenoemde beperkingen en overwegingen, heb ik het voorrecht gehad schilderijen 
te mogen bestuderen van beroemde en minder beroemde kunstenaars. Velen hebben geleefd en gewerkt in de Lage Landen. Mijn ervaring heb ik bijeen gebracht in een recent verschenen kunstboek "De kunstenaar en de dokter/Anders kijken naar schilderijen", waarin 216 schilderijen zijn opgenomen met 292 ziektebeelden. ${ }^{4}$ Dit boek bevat naast een wezenlijke beschrijving van de medische diagnose, termen en symptomen, die nodig zijn om de klinische bevindingen en de voorgestelde diagnose te staven, anekdotische informatie over de kunstenaar en zijn onderwerp en over de historische periode waarin het kunstwerk tot stand kwam, maar wel steeds vanuit een medische invalshoek. De klinische diagnose werd systematisch gesteld op basis van de methodiek die ik als hoogleraar in het probleemgeoriënteerd onderwijs en klinisch redeneren met videobeelden heb gedoceerd. ${ }^{5}$ Dat wil zeggen: eerst de hoofdafwijking(en) noteren, vervolgens de gegevens die de context bepalen als leeftijd, geslacht, kleding, beroep..... en tenslotte het formuleren van de meest passende klinische diagnose en eventueel alternatief.

Tekens van alle mogelijke systeemziekten heb ik gevonden bij grote meesters als Jan van Eyck, Jacob Jordaens, Quinten Metsijs, Albrecht Dürer, Sandro Botticelli, Pieter Paul Rubens, Pieter Brueghel, Velasquez, Dirk Bouts, Leonardo da Vinci, Rembrandt, en ook bij Vincent van Gogh, Pablo Picasso en bij nog veel anderen. Meerdere gevallen werden in internationale medische en kunsthistorische tijdschriften gepubliceerd.

De processie van de kreupelen van Jheronimus Bosch (of leerling) in het Albertina Museum in Wenen is een leerrijk voorbeeld van de epidemiologie van gehandicapten in 1500 (zie figuur 1). In de Lage Landen was het de gewoonte dat op maandag en dinsdag na Driekoningen de leprozen in processie door de stad trokken voor een algemene collecte. Bosch typeerde op een meesterlijke wijze de verscheidenheid van aandoeningen die aanleiding gaven tot kreupelheid. Daar er in 1500 niet zoveel nieuwe gevallen van lepra waren, werden ook andere kreupelen opgenomen in de leprozerie. 31 gevallen zijn weergegeven op deze kleine tekening. In samenwerking met een orthopeed en een neuroloog heb ik bij al deze gevallen een diagnose kunnen stellen. ${ }^{6}$ De ziekten varieerden van infectueuze, traumatische en aangeboren aandoeningen tot hysterisch gerelateerde aandoeningen. Noch lepra, noch syfilis blijken in 1500 de belangrijkste oorzaken van kreupelheid te zijn.

Figuur 2 toont een selectie van de meest demonstratieve gevallen en hun diagnosen: alcoholisme, spina bifida (open ruggemerg), ergotisme, spastische triplegische verlamming, arthrogryposis, neuropatie ten gevolge van syfilis, blindheid, tibiale (onderbeen) agenese,

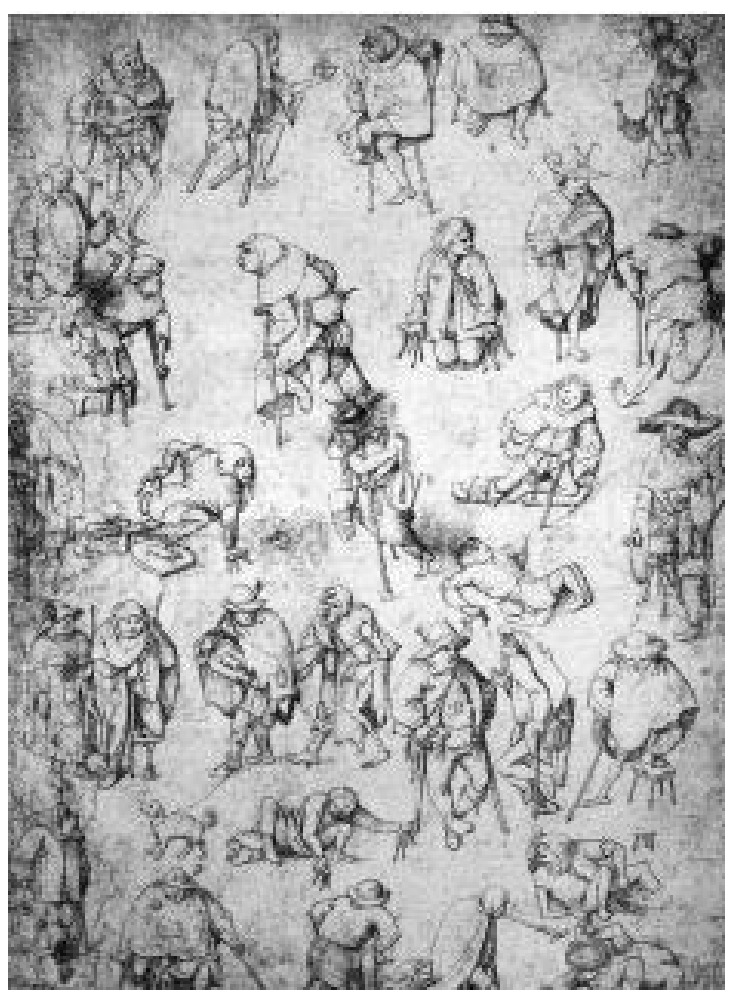

Figuur 1 De processie van de kreupelen, Jheronimus Bosch (of leerling) ca 1500, Albertina Museum Wenen.

hemiplegie (halfzijdige verlamming), tuberculose van de wervelzuil (ziekte van Pott) en sacrale agenese.

Bij de voltooiing van mijn boek heb ik twee dingen geleerd. In de eerste plaats heb ik kunnen vaststellen dat symptomen van veel zogenaamde moderne ziekten

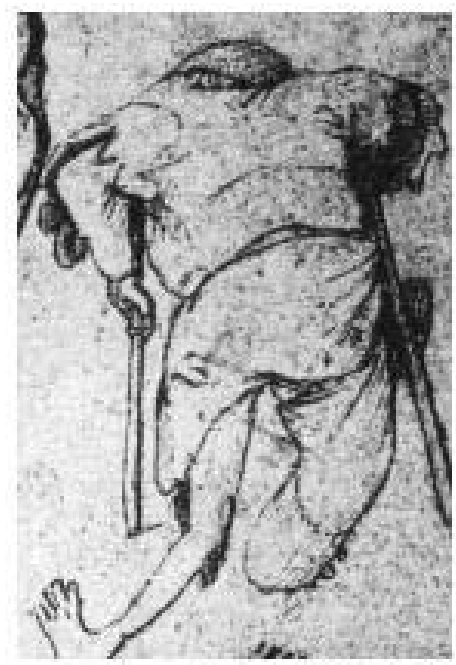

Neuropatie

Figuur 2 Details van de processie van de kreupelen, Jheronimus Bosch (of leerling) ca 1500, Albertina Museum Wenen. 


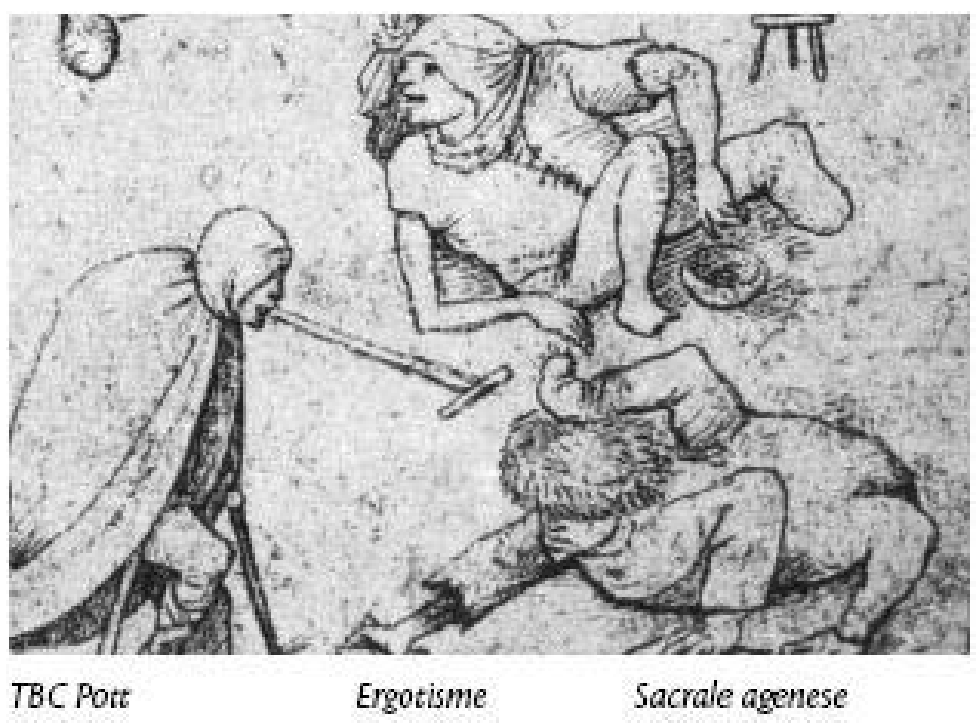

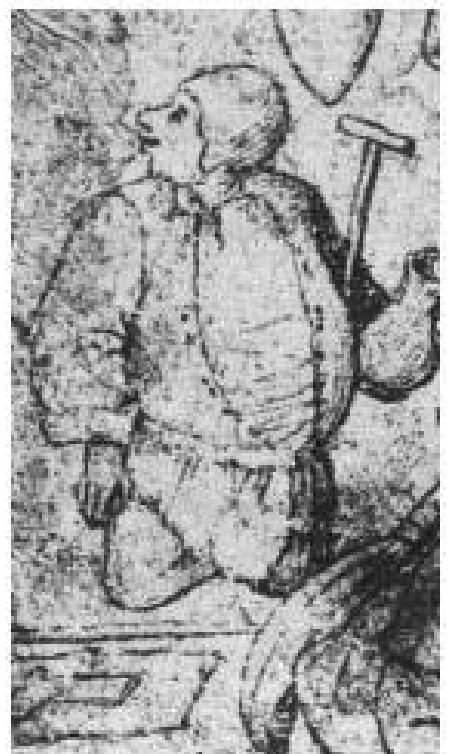

Valse bedelaar

alcoholisme

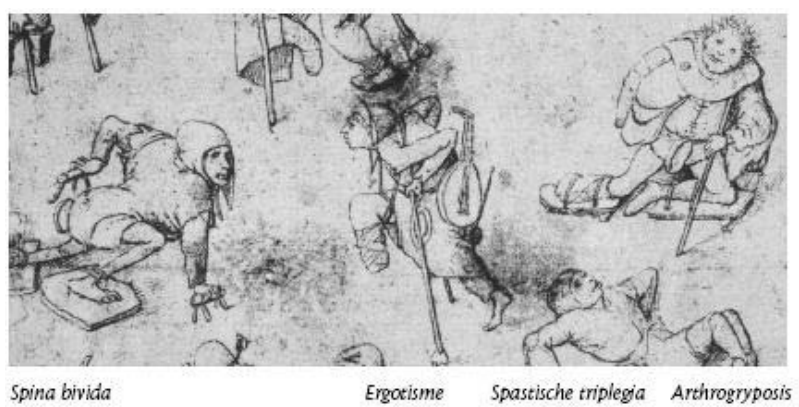

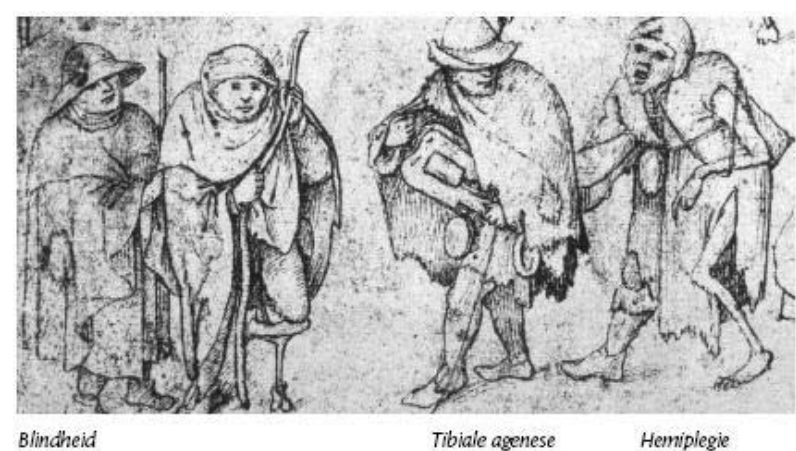

eeuwen geleden al door kunstenaars zijn opgemerkt, lang voordat artsen dit deden. Ten tweede dat een goede observatie een sleutelrol speelt in de klinische geneeskunde, ook nog in deze tijd.

\section{Literatuur}

Copeman WSC. A short history of the gout and the rheumatic diseases. University of California Press Berkeley and Los Angeles; 1964; p237.

Short CL. The antiquity of rheumatoid arthritis. Arthritis Rheum 1974; 17:193-208.

Dequeker J. Paleopathology of rheumatism in paintings. In: Human Paleopathology: Current syntheses and future options. Ortner JJ \& Aufderheide AC. editors, Washington Smithsonian Institution Press 1991; p216-21.

Dequeker J. De kunstenaar en de dokter/Anders kijken naar schilderijen. Davidsfonds /Leuven 2006 p413 ISBN 90-5826-338$\mathrm{X}$.

Dequeker J, Jaspaert R. Teaching problem-solving and clinical reasoning: 20 years experience with video-supported smallgroup learning. Med Educ 1998;32:384-9.

Dequeker J., Fabry G.,Vanopdenbosch L. De processie van kreupelen naar Jeroen Bosch (ca1450-1516): een historische analyse. Millenium Tijdschrift voor middeleeuwse studies 2000;15:140-153. 